Tropical Journal of Pharmaceutical Research March 2018; 17 (3): 499-505

ISSN: $1596-5996$ (print); 1596-9827 (electronic)

(C) Pharmacotherapy Group, Faculty of Pharmacy, University of Benin, Benin City, 300001 Nigeria.

Available online at http://www.tjpr.org

Original Research Article

http://dx.doi.org/10.4314/tjpr.v17i3.16

\title{
Lipolytic and antimicrobial activities of Pseudomonas strains isolated from soils in Phetchaburi Province, Thailand
}

\author{
Paranee Sripreechasak ${ }^{1,2}$, Wongsakorn Phongsopitanun ${ }^{3}$, Khomsan Supong ${ }^{4}$, \\ Somboon Tanasupawat ${ }^{1 *}$
}

${ }^{1}$ Department of Biochemistry and Microbiology, Faculty of Pharmaceutical Sciences, Chulalongkorn University, Bangkok 10330, ${ }^{2}$ Department of Biotechnology, Faculty of Science, Burapha University, Chonburi, 20131, ${ }^{3}$ Department of Biology, Faculty of Science, Ramkhamhaeng University, Bangkok10240, ${ }^{4}$ Department of Applied Science and Biotechnology, Faculty of AgroIndustrial Technology, Rajamangala University of Technology, Twan-ok Chantaburi Campus, Chantaburi 22210, Thailand

*For correspondence: Email: Somboon.T@chula.ac.th; Tel: +66-2-218-8376; Fax: +66-2-254-5195

\begin{abstract}
Purpose: To identify and determine lipolytic and antimicrobial activities, and antibiotic susceptibility of bacterial isolates from soils in Phetchaburi Province, Thailand.

Methods: Bacterial strains were isolated from surface soils by enrichment technique using lipolytic broth (LB) and then identified based on their phenotypic and genetic characteristics. The cell-free culture supernatant was determined for lipase activity by spectrophotometric assay. Disc diffusion assay was used to determine the crude ethyl acetate extract of the culture supernatant for antimicrobial activity and antibiotic susceptibility. The chemical profile of the crude ethyl acetate extract was analyzed by reverse-phase C-18 column high-performance liquid chromatography (HPLC).

Results: On the basis of phenotypic properties and their 16S rRNA gene sequence analysis, five bacterial isolates, P1-2, P1-5, P1-6, P1-10 and P1-20 were identified as strains of Pseudomonas with sequence similarities (99.7-100\%). The extracellular lipase activity in LB supplemented with $1 \%(\mathrm{~V} / \mathrm{V})$ of each of Tween 20, Tween 40, 60 or 80 as the substrate ranged from $11.61 \pm 0.61$ to $15.09 \pm 0.42$, $11.79 \pm 0.28$ to $15.75 \pm 0.47,12.65 \pm 0.01$ to $14.59 \pm 0.87$ and $12.71 \pm 0.25$ to $13.96 \pm 0.21$ unit $/ \mathrm{mL}$, respectively. The crude ethyl acetate extract of isolates P1-5, P1-6 and P1-20 contained quinoline alkaloid compounds and exhibited antibacterial activity against Gram-positive Kocuria rhizophila ATCC 9341 and Staphylococcus aureus strains ATCC 25923, ATCC 6358 and ATCC 25913, but not against Gram-negative Escherichia coli ATCC 25922. All the isolates were susceptible to cefepime, cefotaxime, ceftriaxone, ceftazidime, amikacin, gentamicin, imipeneum, meropeneum and levofloxacin.

Conclusion: The isolates demonstrate high lipolytic activity while the crude extracts exhibit antibacterial activity against Gram-positive bacteria. Thus, this lipase is a potential enzyme for pharmaceutical applications.
\end{abstract}

Keywords: Antibiotic susceptibility, Antimicrobial activity, Lipolytic activity, Pseudomonas, Thai soil

This is an Open Access article that uses a funding model which does not charge readers or their institutions for access and distributed under the terms of the Creative Commons Attribution License (http://creativecommons.org/licenses/by/4.0) and the Budapest Open Access Initiative (http://www.budapestopenaccessinitiative.org/read), which permit unrestricted use, distribution, and reproduction in any medium, provided the original work is properly credited.

Tropical Journal of Pharmaceutical Research is indexed by Science Citation Index (SciSearch), Scopus, International Pharmaceutical Abstract, Chemical Abstracts, Embase, Index Copernicus, EBSCO, African Index Medicus, JournalSeek, Journal Citation Reports/Science Edition, Directory of Open Access Journals (DOAJ), African Journal Online, Bioline International, Open-J-Gate and Pharmacy Abstracts 


\section{INTRODUCTION}

Pseudomonas species are Gram-negative, aerobic, non-spore forming bacilli with one or more polar flagella. They are widely found in natural environments, especially in the soil and water [1]. Some Pseudomonas strains are opportunistic pathogens and resistant to different classes of antibiotics [2]. In general they show variable and increasing levels of antimicrobial resistance, an observation that has generated considerable health concern [3]. However, Pseudomonas strains have been studied in many fields of medicine, food technology, environmental microbiology and pathology. They are producers of extracellular enzymes, including lipases, proteases and amylases [4]. Lipases from $P$. aeruginosa strains have been widely studied, because they display activity on alkaline media, a characteristic needed for use in detergents [5-7].

Lipases (triacylglycerol acylhydrolases, EC 3.1.1.3) are solvable enzymes that show the capability to hydrolyze triacylglycerols to liberate free fatty acids and glycerol [8]. They catalyze the separating of carboxyl ester bonds in tri-, diand mono-acylglycerols and catalyze others reactions, including acidolysis, alcoholysis, esterification, hydrolysis and transesterification $[9,10]$. Moreover, lipases are valuable biocatalysts with potential application in many industries, such as the food, medicine, chemical, bioenergy, leather, paper and detergent $[9,11]$. In addition, twelve 4-hydroxyquinoline derivatives and three phenazine alkaloids have been isolated from $P$. aeruginosa BCC 76810 [12].

The objective of this study was to determine the extracellular lipolytic activity, antimicrobial activity and antibiotic susceptibility of new Pseudomonas strains isolated from soils in Thailand.

\section{EXPERIMENTAL}

\section{Isolation and identification of isolates}

Three surface soil samples (0 - $5 \mathrm{~cm}$ depth) were collected from palm fields in Phetchaburi Province, Thailand. Bacterial strains were isolated using 1 gram of the soil sample enriched in $9 \mathrm{~mL}$ lipolytic broth (LB) composed (w/v) of peptone $1 \%, \mathrm{CaCl}_{2} \cdot 2 \mathrm{H}_{2} \mathrm{O} 0.01 \%$, yeast extract $0.3 \%$ and Tween $201 \% \quad(\mathrm{v} / \mathrm{v})$ as substrate and incubated at $37{ }^{\circ} \mathrm{C}$ for $48 \mathrm{~h}$. The suspension was then streaked on lipolytic agar (LA; LB plus agar $1.5 \%(w / v)$ ) and incubated at $37^{\circ} \mathrm{C}$ for $48 \mathrm{~h}$. Colonies that showed an opaque zone on LA medium were selected and purified to single colonies on tryptic soy agar (TSA) for further study.

The phenotypic characteristics of each strain, including morphological, cultural, physiological and biochemical characteristics, were determined via Gram staining, cell morphology, catalase, oxidase and nitrate reduction activity; methyl red-Voges Proskauer (MR-VP), indole, urease, triple sugar iron (TSI) agar and citrate utilization; hydrolysis of starch, aesculin, casein, gelatin and arginine and acid production from carbohydrates [13]. Growth in different salt concentrations $(1-10 \% \mathrm{NaCl}(\mathrm{w} / \mathrm{v})$ in integer increments), $\mathrm{pH}$ values $(4-10$ in integer increments) and temperatures (20, 30, 37, 40, 45 and $50{ }^{\circ} \mathrm{C}$ ) was tested. Antibiotic susceptibility was examined by the disc diffusion assay [14] on Mueller-Hinton agar (Difco).

The PCR amplification of 16S rRNA gene of lipase-producing bacteria was carried out using the primers 20F (5'-AGTTTGATCCTGGCTC-3') and 1530R (5'-AAGGAGGTGATCCAGCC-3') as reported previously [15]. The PCR products were direct sequenced commercially (Macrogen Inc, Seoul, Korea) using universal primers [15] and the obtained sequences were screened for similar homologues using BLASTn analysis via EzTaxon-e server (http://ezbiocloud.net/eztaxon) [16]. Sequences were aligned for comparison with sequences from close homologues and member of the genus Pseudomonas using the Bioedit software (Ibis Biosciences, Carlsbad, CA, USA). The phylogenetic tree, neighbor-joining (NJ) distance method [17], was built using the MEGA version 6 software [18]. The bootstrap resampling with 1000 replicates was used for evaluating the confidence values of nodes in the phylogenetic tree [19]. The 16S rRNA fragment sequences for isolates P1-2, P1-5, P1-6, P1-10 and P1-20 have been deposited in GenBank with accession codes LC215417-LC215421, respecttively.

\section{Determination of lipase activity}

Isolates were screened for lipolytic activity on LA plates, except that where indicated the $1 \%(\mathrm{v} / \mathrm{v})$ substrate was changed from Tween 20 to each of Tween 40, Tween 60 or Tween 80 [13]. Isolates were first cultivated on TSA for $24 \mathrm{~h}$ and then suspended in $0.85 \%(w / v)$ normal saline solution (NSS). The cell suspension $(5 \mu \mathrm{L})$ was dropped onto the surface of each LA plate and incubated at $37^{\circ} \mathrm{C}$ for $48 \mathrm{~h}$. The lipolytic activity of the isolates was detected by the appearance of an opaque zone around the colonies. Isolates that showed a lipolytic activity to the different substrates on LA plates were selected and 
cultivated on TSA and suspended in $0.85 \%$ NSS $\left(2 \times 10^{8} \mathrm{CFU} / \mathrm{mL}\right)$ for seed culture as mentioned above. Thereafter, $1 \%(\mathrm{v} / \mathrm{v})$ seed culture of each strain was inoculated into $100 \mathrm{~mL}$ LB $(1 \%(\mathrm{v} / \mathrm{v})$ Tween 20 as substrate) and incubated on a rotary shaker $(200 \mathrm{rpm})$ at $37^{\circ} \mathrm{C}$ for $48 \mathrm{~h}$. The fermentation broth was collected, clarified by centrifugation at $10,000 \mathrm{rpm}$ and $4{ }^{\circ} \mathrm{C}$ for $10 \mathrm{~min}$, and the supernatant was harvested and $50 \mu \mathrm{L}$ aliquots used as a crude enzyme preparation for the lipase activity assay.

Extracellular lipase production was performed in lipase medium (LM; LA without the yeast extract with $1 \%(\mathrm{v} / \mathrm{v})$ substrate of one of Tween 20,40 , 60 or $80, \mathrm{pH} 8.0$ ). The seed culture was prepared in NSS as above. Submerged microbial cultures were cultivated in $500-\mathrm{mL}$ Erlenmeyer flasks containing $100 \mathrm{~mL}$ of LM on a rotary shaker (200 $\mathrm{rpm})$ at $37{ }^{\circ} \mathrm{C}$ for 24,48 and $72 \mathrm{~h}$. After incubation, the cells were precipitated by centrifugation as above, and the cell-free culture supernatant was used as the extracellular crude enzyme for the lipase activity assay. Lipase activity was determined using a modification of the spectrophotometric assay method of Arora [20], using $\rho$-nitrophenyl palmitate ( $\rho$-NPP) as the substrate. The reaction mixture was composed of $50 \mu \mathrm{L}$ of $\rho$-NPP substrate solution and $50 \mu \mathrm{L}$ of the crude enzyme solution. The $\rho$ NPP (30 mg of $\rho$-NPP in isopropyl alcohol) substrate solution was prepared in $0.1 \mathrm{M}$ Tris$\mathrm{HCl}$ buffer, $\mathrm{pH} 8.0$ with $2 \%(\mathrm{v} / \mathrm{v})$ Triton $\mathrm{X}$ and 0.1 $\%(w / v)$ gum arabic. The reaction mixture was incubated at $37^{\circ} \mathrm{C}$ for $30 \mathrm{~min}$, and then stopped by the addition of $100 \mu \mathrm{L}$ of $1 \mathrm{M} \mathrm{NaHCO}_{3}$. Subsequently, the extent of color change resulting from the reaction was measured by reading the absorbance at $410 \mathrm{~nm}$ as reported [20]. All lipase activity assays were performed at least in triplicate.One unit $(U)$ was defined as the amount of enzyme that catalyzes $p$-NPP and releases $1 \mu \mathrm{mol}$ of $\rho$-nitrophenol per minute under the test conditions.

\section{Fermentation, extraction, antimicrobial activity and chemical profile analysis}

The antimicrobial activity of the three selected isolates (P1-5, P1-6 and P1-10) was determined by cultivating in $150 \mathrm{~mL}$ nutrient broth (Difco) at $37{ }^{\circ} \mathrm{C}$ for 4 days. The cultivation medium was partitioned with an equal volume of ethyl acetate, harvesting the ethyl acetate phase and repeating the process three times. The final ethyl acetate layer was collected and evaporated to dryness to yield the crude ethyl acetate extract of the supernatant (CEAESN). The antibacterial activity of the CEAESN was determined using the agar disc diffusion method, against the Gram-positive bacteria Kocuria rhizophila ATCC 9341, Staphylococcus aureus ATCC 25923, ATCC 6538P and ATCC 25913, the Gram-negative Escherichia coli ATCC 25922 plus for antifungal activity the yeast, Candida albicans ATCC 10231. The cell density of the test microorganisms was adjusted to match the 0.5 McFarland turbidity standard. Each cell suspension of tested microorganism was swabbed onto the surface of a TSA plate or sabouraud dextrose agar for the bacteria and yeast, respectively. To prepare the test paper discs, the crude extract was dissolved in methanol. To each $6-\mathrm{mm}$ paper disc, $20 \mu \mathrm{L}$ of crude extract $(10 \mathrm{mg} / \mathrm{mL})$ was added, and the discs were air-dried. Paper discs treated with 20 $\mu \mathrm{L}$ methanol were used as the negative control. The paper discs were placed on the surface of the agar media containing the test microorganisms and incubated at $30{ }^{\circ} \mathrm{C}$ for $48 \mathrm{~h}$ for yeast and $37{ }^{\circ} \mathrm{C}$ for $24 \mathrm{~h}$ for bacteria. The inhibition zones were then measured using Vernier calipers to the nearest $\mathrm{mm}$.

For the chemical profile analysis, the CEAESN was dissolved in methanol $(10 \mu \mathrm{g} / \mathrm{mL})$ and then analyzed by HPLC, with elution via a linear gradient $\left(0-100 \%(\mathrm{v} / \mathrm{v}) \mathrm{CH}_{3} \mathrm{CN}\right.$ in $\left.\mathrm{H}_{2} \mathrm{O}\right)$ over 15 min at a flow rate of $0.5 \mathrm{~mL} / \mathrm{min}$, using a C-18 column $(3 \mu \mathrm{m}), 2 \times 55 \quad \mathrm{~mm}$ (Purospher ${ }^{\circledR}$ STAR;Merck) [12]. The HPLC was performed on a Dionex-Ultimate 3000 series equipped with a binary pump, an autosampler and a diode array detector. The crude extract was compared with the database of BRUPC code and the chemical data were analyzed using the pattern of UV spectra and retention time (RT) of HPLC detection. In addition, the chemical data of the metabolites from the selected strains were compared with the reported metabolite profiles of Pseudomonas aeruginosa BCC 76810 [12].

\section{Statistical analysis}

Data shown as mean \pm standard deviation (SD, $\mathrm{n}$ $=3$ ), and were analysed by one-way ANOVA and separated by Duncan's multiple-range test using the SPSS 16.0 software (SPSS Inc., Chicago, IL, USA). Statistical significance was assigned at $p$ $<0.05$.

\section{RESULTS}

\section{Identified isolates}

The five new- soil-derived isolates screened in this study, P1-2, P1-5, P1-6, P1-10 and P1-20 were Gram-negative, aerobic and rod-shaped bacteria. Their morphology, Gram-staining and physiological and biochemistry characteristics 


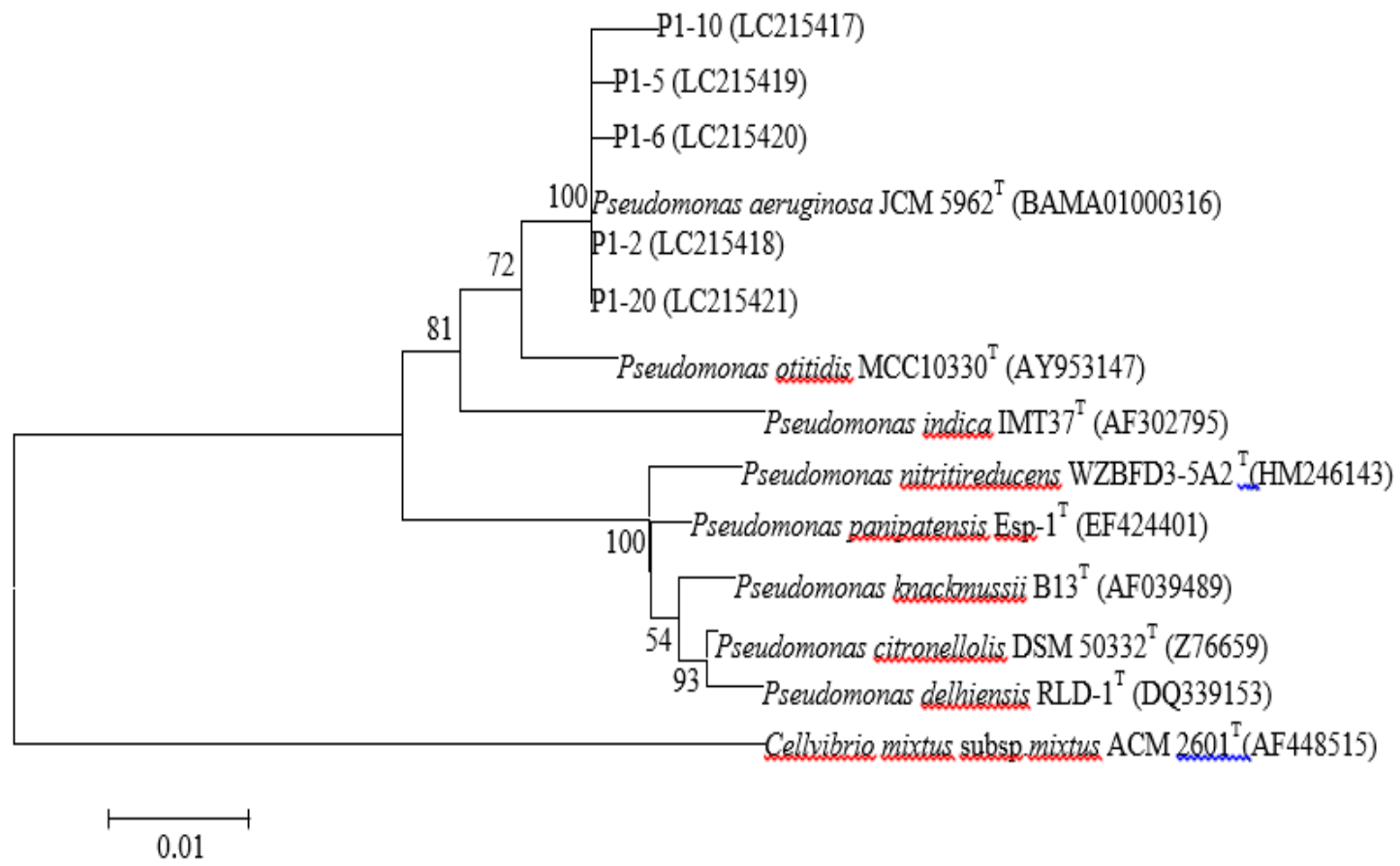

Figure 1: Neighbor-joining tree based on 16S rRNA gene sequences showing the relationships among the five new isolates and related Pseudomonas species. The numbers on the branches indicate the percentage bootstrap values of 1000 replicates; with only values $>50$ being indicated. Bar, represents 0.01 substitutions per nucleotide position

are described below. Isolates $\mathrm{P} 1-10$ and $\mathrm{P} 1-20$ grew on $7 \% \mathrm{NaCl}(\mathrm{w} / \mathrm{v})$ at 40 and $45{ }^{\circ} \mathrm{C}$, respectively. They tested positive for catalase and oxidase activity, nitrate reduction, citrate utilization, and hydrolysis of arginine, casein and gelatin but were negative for aesculin and starch hydrolysis, MR-VP, indole formation, urease and TSI activity as well as acid production from Larabinose, D-cellobiose, D-fructose, D-galactose, D-glucose, glycerol, myo-inositol, inulin, lactose, D-maltose, D-mannitol, D-mannose, D-melibiose, D-melezitose, methyl- $\alpha$-D-glucopyranoside, Draffinose, L-rhamnose, D-ribose, D-sorbitol, sucrose, D-trehalose and D-xylose. In terms of antibiotic susceptibility, all the isolates were susceptible to cefepime, cefotaxime, ceftriaxone, ceftazidime, amikacin, gentamicin, imipeneum, meropeneum and levofloxacin.

For molecular taxonomic unit (MOTU) identification, the nearly complete 16S rRNA gene sequences obtained from isolates $\mathrm{P} 1-2$ (1372 bp), P1-5 (1357 bp), P1-6 (1320 bp), P110 (1389 bp) and P1-20 (1343 bp) were used to constructed a NJ phylogenetic tree along with related Pseudomonas species (Figure 1). The Gram-negative Cellovibrio mixtus subsp. mixtus was used as the out group. All five isolates were placed in the same clade as the type strain of $P$. aeruginosa but separated from the other Pseudomonas species.

\section{Lipase activity}

After incubation in LB at $37^{\circ} \mathrm{C}$ for 24,48 and 72 $\mathrm{h}$, the five isolates, P1-2, P1-5, P1-6, P1-10 and $P 1-20$ exhibited lipase activities $(\mathrm{U} / \mathrm{mL})$ with all substrates and the cultivated times, but for each substrate was maximal at 48-72 $\mathrm{h}$ except for isolate P1-2 with Tween 20 and isolate P1-5 with Tween 20 or Tween 40, where the lipase was not maximal until after $72 \mathrm{~h}$ (Figure 2). With respect to the substrate, each isolate exhibited broadly similar extracellular lipase activity after cultivated for $72 \mathrm{~h}$ on each of the substrate, except for P1-2 that had a slightly higher lipase activity in Tween 20 and Tween 40. However, the initial extracellular lipase activity ( $24 \mathrm{~h}$ ) was typically lower in Tween 20 and the highest was in Tween 60 , and was especially low for isolate P1-20 in all substrates. The maximal extracellular lipase activity produced by the different isolates after 72 $h$ culture ranged from $11.79 \pm 0.28 \mathrm{U} / \mathrm{mL}(\mathrm{P} 1-10$ in Tween 40) up to $15.75 \pm 0.47 \mathrm{U} / \mathrm{ml}(\mathrm{P} 1-5$ in Tween 40).

\section{Antimicrobial activity and chemical profile of crude extract}

The crude extract exhibited antibacterial activity against $K$. rhizophila ATCC 9341 and S. aureus ATCC 25923, ATCC 6358 and ATCC 25913, but not against E. coli ATCC 25922 and C. albicans ATCC 10231 (Table 1). Analysis of the chemical profiles (RT) of the crude ethyl acetate extracts 

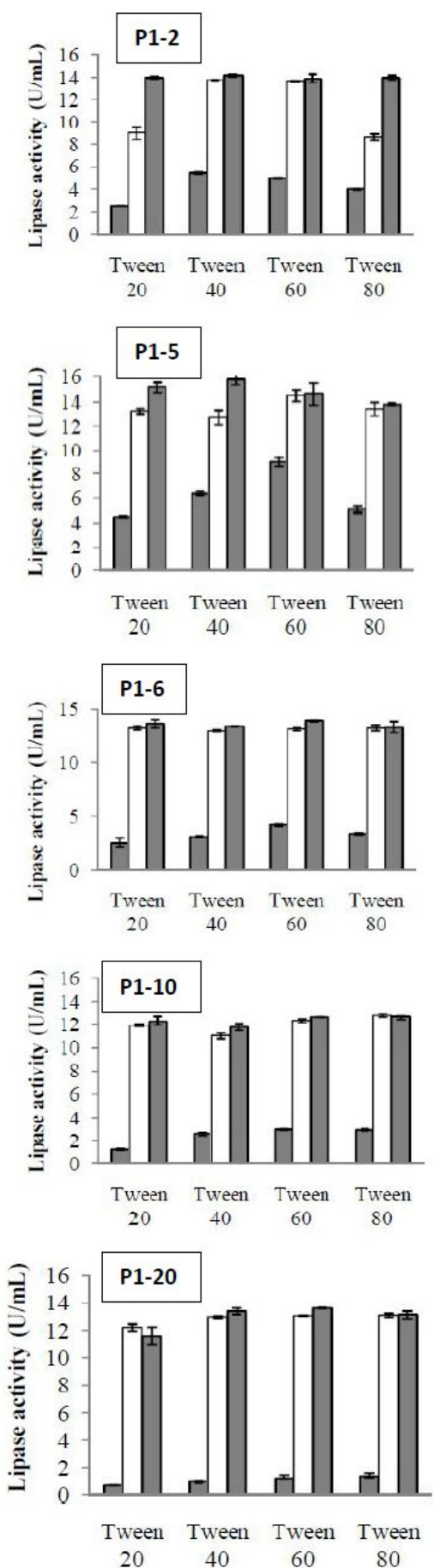

Figure 2: Lipase activities $(\mathrm{U} / \mathrm{mL})$ of isolates $P 1-2$, $\mathrm{P} 1-5, \mathrm{P} 1-6, \mathrm{P} 1-10$ and $\mathrm{P} 1-20$ in LB containing $1 \%$ (v/v) Tween 20, Tween 40, Tween 60 or Tween 80 as substrate at $37^{\circ} \mathrm{C}$ for 24,48 and $72 \mathrm{~h}$ of each of the three isolates, P1-5, P1-6 and P120 using HPLC fractionation over a C-18 silica column and UV analysis of the eluate RT compared the database [BRUPC code and RT, 493, 6.175; 472, 6.192; 506, 7.050; and 497, 7.542 , respectively], shown that the crude extract was identical to quinolone alkaloid compounds [12].

\section{DISCUSSION}

PCR amplification and direct sequencing of the 16S rRNA gene fragment from the isolates, P1-2 (1372 bp), P1-5 (1357 bp), P1-6 (1320 bp), P110 (1389 bp), and P1-20 (1343 bp), followed by sequence comparison and phylogenetic analysis revealed that all five new isolates were from the same molecular taxonomic unit and presented the same morphological, physiological and biochemical data as the member of the genus Pseudomonas. Therefore, there were identified as $P$. aeruginosa. These isolates were susceptible to cefepime, cefotaxime, ceftriaxone, ceftazidime, amikacin, gentamicin, imipeneum, meropeneum and levofloxacin as reported in $P$. aeruginosa strains [2, 1] and their susceptibility to amikacin and meropeneum was also the same as in $P$. aeruginosa isolated from patients [22]. These five isolates exhibited high extracellular lipase activity; a trait found in some other $P$. aeruginosa strains, where the lipases have been purified and characterized and found to active in organic solvents and suitable for a variety of applications, including reactions in waterrestricted medium and bioremediation of contaminations by organic solvents [23,24]. The CEAESN from three of the isolates, P1-5, P1-6 and $\mathrm{P} 1-20$ were found to produce quinoline alkaloid compounds that showed antimicrobial activity against Gram-positive bacteria, $K$. rhizophila and $S$. aureus, but not Gram-negative, $E$. coli the same activity of pyocyanin produced by $P$. aeruginosa strains from surgical woundinfections [25]. The quinoline series of compounds have previously been shown to exhibit antimalarial activity against the $\mathrm{K} 1$ strain of Plasmodium falciparum, in vitro cytotoxicity against cancer (KB, MCF-7, NCl-H187) and noncancer (Vero) cells and antibacterial activity

Table 1: Antimicrobial activities of the crude ethyl acetate extract of three $P$. aeruginosa isolates

\begin{tabular}{lcccccc}
\hline \multirow{2}{*}{$\begin{array}{l}\text { Isolate } \\
\text { no. }\end{array}$} & $\begin{array}{c}\text { K. } \\
\text { rhizophila }\end{array}$ & $\begin{array}{c}\text { S. aureus } \\
\text { ATCC }\end{array}$ & $\begin{array}{c}\text { S. aureus } \\
\text { ATCC 6538P }\end{array}$ & $\begin{array}{c}\text { S. aureus } \\
\text { ATCC 25913 }\end{array}$ & $\begin{array}{c}\text { E. coli } \\
\text { ATCC 25922 }\end{array}$ & $\begin{array}{c}\text { C. albicans } \\
\text { ATCC 10231 }\end{array}$ \\
\hline P1-5 & $24.5 \pm 0.7$ & 25923 & & & & \\
P1-6 & $24.8 \pm 0.4$ & $22.3 \pm 1.0$ & $24.8 \pm 1.0$ & $20.5 \pm 0.7$ & - & - \\
P1-20 & $24.0 \pm 0.4$ & $21.4 \pm 0.8$ & $27.3 \pm 1.0$ & $22.5 \pm 0.7$ & - & - \\
\hline
\end{tabular}

- = no inhibition zone. SD values were obtained from two independent determinations 
against Bacillus cereus [12].

\section{CONCLUSION}

The findings of the present study indicate that $P$. aeruginosa isolated from soils in Thailand possess lipolytic and antibacterial activities. These findings may be helpful in understanding the distribution of lipase-producing $P$. aeruginosa from soils other than clinical isolates.

\section{DECLARATIONS}

\section{Acknowledgement}

This study was supported by the Grant for International Research Integration: Research Pyramid, Ratchadaphiseksomphot Endowment Fund (No. GCURP 580133 01), Chulalongkorn University. Additional thanks to the Ratchadapiseksomphot Endowment Fund, Chulalongkorn University for a post-doctoral fellowship to Dr. Paranee Sripreechasak.

\section{Conflict of interest}

There is no conflict of interest associated with this work.

\section{Contribution of authors}

We declare that this work was done by the authors named in this article and all liabilities pertaining to claims relating to the content of this article will be borne by the authors. Paranee Sripreechasak and Somboon Tanasupawat designed the study, performed experiment on isolation, identification and assay of the lipase activity. Wongsakorn Phongsopitanun and Khomsan Supong determined the antimicrobial activity and chemical profile. All authors read and approved the final manuscript.

\section{REFERENCES}

1. Warghane AJ, Wagh GN, Nag BB SP, Jisnani $M L$, Thaware RR, Kitey HS. Isolation and characterization of Pseudomonas species from Godavari River sample. Asiatic J Biotech Res 2011; 2: 862-866.

2. Javiya VA, Ghatak SB, Patel KR, Patel JA. Antibiotic susceptibility patterns of Pseudomonas aeruginosa at a tertiary care hospital in Gujarat, India. Indian J Pharmacol 2008; 40: 230-234.

3. Falodun OI, Adekanmbi AO. Antibiogram of Escherichia coli and Pseudomonas strains isolated from wastewater generated by an abattoir as it journeys into a receiving river. Adv Microbiol 2016; 6: 303-309.
4. Khannous L, Jrad M, Dammak M, Miladi R, Chaaben $N$, Khemakhem B, Gharsallah $N$, Fendri I. Isolation of a novel amylase and lipase-producing Pseudomonas luteola strain: study of amylase production conditions. Lipids Health Dis 2014; 13: 1-9.

5. Gilbert EJ, Comish, Jones C. Purification and properties of extracellular lipase from Pseudomonas aeruginosa EF2. J Gen Microbiol 1991; 137: 2223-2229.

6. Shabtai Y, Daya-Mishne N. Production, purification, and properties of a lipase from a bacterium (Pseudomonas aeruginosa Y8-7) capable of growing in water- restricted environments. Appl Environ Microbiol 1992; 98: 174180.

7. Pahneros B, Güereca L, Alagón A, Soberbón-Chávez, G. Biochemical characterization of the lipolytic activity of Pseudomonas aeruginosa IG B 83. Process Biochem 1994; 29: 207-212.

8. Kumara D, Parshad R, Gupta V K. Application of a statistically enhanced, novel, organic solvent stable lipase from Bacillus safensis DVL-43. Int. J Biol Macromol 2014; 66: 97-107.

9. Guo J, Chen C-P, Wang S-G, Huang X-J. A convenient test for lipase activity in aqueous-based solutions. Enzyme Microbial Technol 2015; 71: 8-12.

10. Stergiou P-Y, Foukis A, Filippou $M$, Koukouritaki $M$, Parapouli M, Theodorou LG, Hatziloukas E, Afendra A, Pandey A, Papamichael EM. Advances in lipasecatalyzed esterification reactions. Biotechnol Advances 2013; 31: 1846-1859.

11. Yu S, Yu S, Han W, Wanga H, Zheng B, Feng Y. A novel thermophilic lipase from Fervidobacteriumnodosum Rt17-B1 representing a new subfamily of bacterial lipases. J. Mol Catal B: Enzym 2010; 66: 81-89.

12. Supong $K$, Thawai $C$, Supothina $S$, Auncharoen $P$, Pittayakhajonwut $P$. Antimicrobial and anti-oxidant activities of quinoline alkaloids from Pseudomonas aeruginosa BCC 76810. Phytochem Lett 2016; 17: 100106.

13. Barrow GI, Feltham RKA. Cowan and Steel's Manual for the Identification of Medical Bacteria, 3rd edn. Cambridge: Cambridge University Press; 1993.

14. Acar JF, Goldstein FW. Disk susceptibility testing. In: Lorian $V$, editor. Antibiotics in laboratory medicine, 3rd ed. Baltimore: Williams \& Wilkins; 1991. p.17-52.

15. Lane DJ. 16S/23S rRNA sequencing. In: Stackebrandt E, Goodfellow $M$, editors. Nucleic acid techniques in bacterial systematics, Chichester: Wiley; 1991. p. 115175.

16. Kim OS, Cho YJ, Lee K, Yoon SH, Kim M, Na H, Park SC, Jeon YS, Lee JH, Yi H, Won S, Chun J. Introducing EzTaxon-e: a prokaryotic 16S rRNA gene sequence database with phylotypes that represent uncultured species. Int J Syst Evol Microbiol 2012; 62: 716-721.

17. Saitou N,Nei M. The neighbor-joining method: a new method for reconstructing phylogenetic trees. Mol Biol Evol 1987; 4: 406-425. 
18. Tamura K, Stecher G, Peterson D, Filipski A, Kumar S. MEGA6: molecular evolutionary genetics analysis version 6.0. Mol Biol Evol 2013; 30: 2725-2729.

19. Felsenstein J. Confidence limits on phylogenies: an approach using the bootstrap. Evolution 1985; 39: 783791.

20. Arora PK. Staphylococcus lipolyticus sp. nov., a new cold-adapted lipase producingmarine species. Ann Microbiol 2013; 63: 913-922.

21. Rall TW, Schleifer LS. Drugs effective in the therapy of the epilepsies. In: Gilman AG, Goodman LS, Rall TW, Murad F, editors. The pharmacological basis of therapeutics, 7th ed., New York: Macmillan Publishing Co; 1985. P. 446-472.

22. Samad A, Ahmed T, Rahim A, Khalil A, Ali I. Antimicrobial susceptibility patterns of clinical isolates of
Pseudomonas aeruginosa isolated from patients of respiratory tract infections in a Tertiary Care Hospital, Peshawar. Pak J Med Sci 2017; 33: 670-674.

23. Stuer W, Jaeger KE, Winkler UK. Purification of extracellular lipase from Pseudomonas aeruginosa. J Bacteriol 1986; 168: 1070-1074.

24. Izrael-Zivkovic LT, Gojgic-Cvijovic GĐ, Gopcevic KR, Vrvic MM, Karadzic IM. Enzymatic characterization of 30 $\mathrm{kDa}$ lipase from Pseudomonas aeruginosa ATCC 27853. J Basic Microbiol 2009; 49: 452-462.

25. El-Shouny WA, Al-Baidani ARH, Hamza WT. Antimicrobial Activity of pyocyanin produced by Pseudomonas aeruginosa isolated from surgical woundinfections. Intl J Pharm Med Sci 2011; 1: 01-07. 